\title{
Inhibition of in-vitro fertilization of mouse gametes by proteinase inhibitors*
}

\author{
S. A. Beyler† and L. J. D. Zaneveld \\ Departments of Physiology and Biophysics, and Obstetrics and Gynecology, University of Illinois \\ at the Medical Center, Chicago, Illinois 60680, U.S.A.
}

\begin{abstract}
Summary. Kinetic studies were performed to evaluate the interaction of benzamidine (BD), 4-aminobenzamidine (ABD), 4'-nitrophenyl 4-guanidinobenzoate (NPGB), and $4^{\prime}$-methylumbelliferyl 4-guanidinobenzoate (MUGB) with mouse acrosin. The Michaelis constant of mouse acrosin towards $\alpha$ - $N$-benzoyl-L-arginine ethyl ester and the sensitivity of mouse acrosin to inhibitors differed from those reported for other species. NPGB and MUGB were much more active inhibitors of acrosin than BD and ABD. Plots of percentage fertilization versus acrosin inhibitor concentration were generated for all 4 compounds. Linear dose-response curves were obtained and gave $\mathrm{ED}_{50}$ values ( $50 \%$ inhibition of fertilization) of $230 \mu \mathrm{M}$ for $\mathrm{BD}, 27 \mu \mathrm{M}$ for $\mathrm{ABD}$, $35 \mathrm{~nm}$ for MUGB, and $13 \mathrm{~nm}$ for NPGB. The relative antifertility activity of the compounds paralleled their inhibitory activity towards mouse acrosin, strongly indicating that the inhibition of fertilization is obtained through the inhibition of acrosin. Since the dose-response curves were linear, the mouse in-vitro fertilization system may be useful to screen acrosin inhibitors for their antifertility potency. MUGB should have low toxicity and may have potential as a contraceptive agent.
\end{abstract}

\section{Introduction}

It is well established that certain synthetic and naturally occurring proteinase inhibitors which inhibit the sperm enzyme acrosin (EC 3.4.21.10), prevent fertilization in vitro and in vivo (for review see Zaneveld, 1976; articles published since then include Greenslade, Hahn \& Homm. 1977; Wolf, 1977; Bhattacharyya, Goodpasture \& Zaneveld, 1979; Joyce, Freund \& Peterson. 1979; Zaneveld, Beyler, Kim \& Bhattacharyya, 1979). These findings imply that acrosin is essential for the fertilization process. However, this interpretation has been criticized because of the lack of specificity of the inhibitors and the possibility that these compounds somehow interfere with sperm function in a non-enzymic manner (Morton, 1976, 1977; Bedford \& Cross. 1978). Therefore, the following experiments were designed to investigate in more detail whether the antifertility effect of proteinase inhibitors is indeed obtained by inhibition of acrosin. Additionally, it was desirable to determine whether an in-vitro fertilization system could be used to measure the relative antifertility potency of enzyme inhibitors.

The mouse in-vitro fertilization system was selected for this study because earlier experiments had indicated its potential usefulness. Two different types of inhibitors were employed: benzamidine (BD) and aminobenzamidine (ABD), and 4'-nitrophenyl 4-guanidinobenzoate

* Reprint requests to Dr L. J. D. Zaneveld.

+ Present address: Department of Biochemistry, Cell, and Molecular Biology, Northwestern University. Fvanston. Illinois 60201, U.S.A. 
(NPGB) and 4'-methylumbelliferyl 4-guanidinobenzoate (MUGB). BD and ABD inhibit acrosin in a reversible fashion by obstructing its active site; whereas NPGB and MUGB bind pseudo-irreversibly with acrosin through complex formation with the active site serine residue.

\section{Materials and Methods}

\section{Materials}

Benzamidine, 4-aminobenzamidine, and 4'-methylumbelliferyl 4-guanidinobenzoate were obtained from Sigma Chemical Co., St Louis, Missouri. 4'-Nitrophenyl 4-guanidinobenzoate was obtained from National Biochemical Co., Cleveland, Ohio, and dimethylsulphoxide (DMSO) was purchased from Fisher Chemicals, Chicago, Illinois.

\section{Extraction and partial purification of acrosin from mouse spermatozoa}

Epididymides were removed from mature Swiss mice and homogenized with a ground-glass tissue grinder in $5 \mathrm{ml}$ of saline $(0.15 \mathrm{M} \mathrm{NaCl})$ which contained $50 \mathrm{~mm}$-sodium phosphate buffer, $\mathrm{pH}$ 7.5. The homogenate was frozen in a solid $\mathrm{CO}_{2}$-acetate bath and immediately thawed at room temperature. This freeze-thaw procedure was repeated twice more, the $\mathrm{pH}$ was adjusted to 2.6 with $1 \mathrm{M}-\mathrm{HCl}$, and the homogenate was stirred at $4^{\circ} \mathrm{C}$ for $15 \mathrm{~h}$. The homogenate was subsequently centrifuged at $27000 \mathrm{~g}$ for $20 \mathrm{~min}$, and the supernatant which contained the acrosin activity was dialysed against 1000 volumes of $1 \mathrm{~mm}-\mathrm{HCl}$ for $4 \mathrm{~h}$. Any proacrosin present was activated to acrosin by incubating the solution at $\mathrm{pH} 8.0$ for 30 min (Bhattacharyya et al., 1979). The $\mathrm{pH}$ was then adjusted again to 3.0 with $\mathrm{HCl}$.

Acrosin was further purified and separated from the acrosin inhibitor that is naturally associated with mouse spermatozoa (Bhattacharyya et al., 1979) by chromatography of the extract on a Sephadex G-100 superfine column which was equilibrated and eluted with 1 $\mathrm{mm}-\mathrm{HCl}$ containing $0.5 \mathrm{M}-\mathrm{NaCl}$. Before loading onto the column, the extract was concentrated to a volume of $0.5 \mathrm{ml}$ by sartorius collodion bag ultrafiltration. The volume of the column was 22 $\mathrm{ml}$. A single peak of acrosin activity was obtained that was free of inhibitor. Due to the small amounts of material, further purification was not possible.

\section{Acrosin inhibition studies}

Mouse acrosin activity was assayed spectrophotometrically by following the hydrolysis of $a-N$-benzoyl-L-arginine ethyl ester (BAEE) at $253 \mathrm{~nm}$ (Schwert \& Takenaka, 1955). Protein was estimated by the method of Lowry, Rosebrough, Farr \& Randall (1951). Various concentrations of the acrosin inhibitors were first incubated with mouse acrosin at ambient temperature in the presence of $50 \mathrm{~mm}-\mathrm{Tris}-\mathrm{HCl}$, $\mathrm{pH} 8.0$ for $5 \mathrm{~min}$. Reactions were initiated by addition of BAEE, and initial rates were determined as:

$$
\left(\Delta A_{253} / \Delta t_{\text {min }}\right) \cdot(1 / 1 \cdot 15 \times E)
$$

where $E$ represents the amount of enzyme used, $A_{253}$ the absorbance at $253 \mathrm{~nm}, \mathrm{t}$ the time interval, and 1.15 the millimolar extinction coefficient for benzoyl arginine (product) at $253 \mathrm{~nm}$. Rates were expressed in terms of $\mu$ mol BAEE hydrolysed per min per mg protein.

Inhibition constants $\left(K_{1}\right)$ for the reversible inhibitors, benzamidine and 4-aminobenzamidine, were determined from plots of reciprocal initial velocities versus inhibitor concentration at BAEE concentrations of 0.1 and $0.5 \mathrm{~mm}$ according to the method of Dixon (1953). For the pseudo-irreversible inhibitors, NPGB and MUGB, plots of initial velocity versus log inhibitor concentration were constructed at the $K_{\mathrm{m}}$ concentration of the substance and concentrations of inhibitor resulting in $50 \%$ inhibition of acrosin activity $\left(I_{50}\right.$ values) were derived. 


\section{In-vitro fertilization studies}

Mature female Swiss albino mice ( $30 \mathrm{~g})$ were injected intraperitoneally with 10 i.u. PMSG (Gestyl: Organon Inc., Oss, The Netherlands), followed 48 h later by 10 i.u. hCG (Antuitrin "S": Parke Davis, Detroit, Michigan). The mice were killed $14 \mathrm{~h}$ after receiving hCG. All subsequent work was performed in a constant-temperature room at $37^{\circ} \mathrm{C}$. The oviducts were excised and placed under sterile silicone oil (200 fluid; Dow Corning Corp., Midland, Michigan) which was pre-warmed to $37^{\circ} \mathrm{C}$ and gassed with a mixture of $5 \% \mathrm{O}_{2}, 5 \% \mathrm{CO}_{2}$, and $90 \% \mathrm{~N}_{2}$. The oocytes in the cumulus masses were teased from the oviducts and immediately transferred to microdishes containing $0.09 \mathrm{ml}$ culture medium under silicone oil. The culture medium consisted of a modified Krebs-Ringer bicarbonate solution containing $2 \mathrm{mg}$ bovine serum albumin (BSA) (Fraction V: Sigma) per $\mathrm{ml}$ as described by Toyoda \& Chang (1974).

Epididymal spermatozoa were obtained by removing each cauda epididymidis from male Swiss mice, and placing them in $1.0 \mathrm{ml}$ capacitation medium after mincing with scissors. The capacitation medium was identical to the culture medium with the exception that $20 \mathrm{mg} \mathrm{BSA} / \mathrm{ml}$ was used. After $5 \mathrm{~min}$, the epididymal tissue was removed, and the spermatozoa were incubated for $1 \mathrm{~h}$ to allow capacitation to occur. During this time, sperm counts were performed and dilutions were made to reach a final concentration of approximately $1 \times 10^{6}$ spermatozoa $/ \mathrm{ml}$ before addition of inhibitors.

Benzamidine and aminobenzamidine were initially dissolved in culture medium at a concentration of $10 \mathrm{~mm}$ with final concentrations ranging from 1 to $500 \mathrm{mM}$. NPGB and MUGB required initial dissolution with $100 \%$ DMSO at a concentration of $10 \mathrm{~mm}$. These stock solutions were subsequently diluted with culture medium such that the final concentrations of these inhibitors ranged from 1 to $5000 \mathrm{nM}$. As controls, the capacitated spermatozoa were incubated with culture medium only (in the case of benzamidine and aminobenzamidine) or with culture medium containing the same amounts of DMSO as the inhibitor solutions (NPGB and MUGB). The final DMSO concentrations were always $<0 \cdot 1 \%$. Before starting the fertilization experiments, the effect of the inhibitor and control solutions upon sperm motility was assessed to ensure that no concentration was used that decreased the motility of the spermatozoa.

After a 15-min preincubation of capacitated spermatozoa with a given concentration of inhibitor, $0.01 \mathrm{ml}$ aliquots of the sperm suspension were added to $0.09 \mathrm{ml}$ medium containing oocytes. Since spermatozoa undergo certain changes as they approach and pass through the investments of the ovum, it was important to keep this concentration of the inhibitors the same throughout the fertilization process. Additionally, benzamidine and aminobenzamidine are reversible inhibitors and probably dissociate from the spermatozoa (and acrosin) during washing or dilution. For these reasons, just before adding the capacitated, inhibitor-treated spermatozoa to the oocytes in the microdish, the same concentration of inhibitor was added to the oocytes to compensate for dilution of the inhibitors at insemination. Control experiments were always performed simultaneously. The microdishes were then incubated at $37^{\circ} \mathrm{C}$ in $5 \% \mathrm{CO}_{2}$ and $100 \%$ relative humidity for $24-26 \mathrm{~h}$. Oocytes were collected with finely drawn glass micropipettes, washed with medium, mounted on slides, fixed with $0.25 \%$ glutaraldehyde followed by $\mathrm{pH} 7$ buffered formalin, washed with $90 \%$ ethanol, and stained with aceto-lacmoid (Toyoda \& Chang, 1974). The stained ova were examined by phase-contrast microscopy for evidence of sperm penetration and cleavage. The criteria for fertilization were the presence of a swollen (decondensing) sperm head, 2 pronuclei in 1 cell ova, or normal cleavage. Dose response curves, generated for the effect of acrosin inhibitors on in-vitro fertilization, were subjected to linear regression analysis.

\section{Inhibition of mouse acrosin}

\section{Results}

The Michaelis constant for BAEE with mouse acrosin was $8.2 \times 10^{-6} \mathrm{M}$. Mouse acrosin activity was inhibited by all 4 inhibitors. Inhibition constants $\left(K_{\mathrm{i}}\right.$ values) for benzamidine and 
aminobenzamidine generated from Dixon plots are shown in Table 1. Benzamidine was less active than amino-benzamidine. NPBG and MUGB both had approximately the same inhibitory activity and were much more effective in inhibiting mouse acrosin than benzamidine and aminobenzamidine (Table 1).

Table 1. Effect of synthetic proteinase inhibitors on mouse acrosin

\begin{tabular}{lcc}
\multicolumn{1}{c}{ Inhibitor } & $K_{\mathrm{i}}(\mathrm{M})^{*}$ & $\mathrm{I}_{50}(\mathrm{M})$ \\
\hline Benzamidine & $5 \cdot 1 \times 10^{-4}$ & - \\
4-Aminobenzamidine & $2.2 \times 10^{-5}$ & - \\
4'-Methylumbelliferyl 4-guanidinobenzoate & - & $9.8 \times 10^{-10}$ \\
4'-Nitrophenyl 4-guanidinobenzoate & - & $8.0 \times 10^{-10}$ \\
\hline
\end{tabular}

* $K_{\mathrm{i}}$ values were derived from Dixon plots, and represent the dissociation constants of the enzyme-inhibitor complexes. $I_{50}$ values represent concentration of inhibitor resulting in $50 \%$ inhibition of enzyme activity.

\section{Inhibition of in-vitro fertilization}

All of the compounds tested had an antifertility effect which correlated with the logarithm of the inhibitor concentration and gave linear log dose-response curves (Text-fig. 1). Inhibitor concentrations which resulted in $50 \%$ inhibition of fertility $\left(\mathrm{ED}_{50}\right.$ values, established via linear regression analysis) were $2.3 \times 10^{-4} \mathrm{M}$ for benzamidine. $2.7 \times 10^{-5} \mathrm{M}$ for aminobenzamidine; $3.5 \times 10^{-8} \mathrm{M}$ for MUGB and $1.3 \times 10^{-8} \mathrm{M}$ for NPGB. Correlation coefficients for the dose-response curves were $0.968,0.981,0.989$ and 0.993 , respectively.

Qualitative analyses of sperm motility during incubation of the spermatozoa and oocytes revealed that sperm motility or forward progression was unaffected by even the highest concentrations of the inhibitors used. Control rates of fertilization ranged from 53 to $95 \%$. The presence of DMSO $(<0 \cdot 1 \%)$ in the NPGB and MUGB controls had no effect upon fertility.

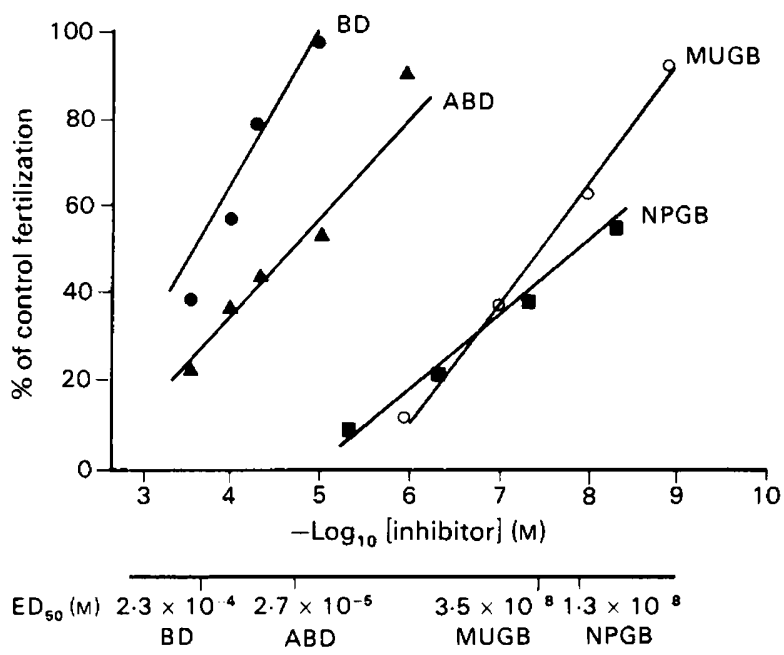

Text-fig. 1. Effect of acrosin inhibitors on mouse fertilization in vitro. Each point represents pooled data from 2-5 separate experiments (50-150 ova). $\mathrm{ED}_{50}$ values below the abscissa represent the concentrations of each compound which caused a $50 \%$ inhibition of fertilization. $\mathrm{BD}$, benzamidine; ABD, aminobenzamidine; MUGB, 4'-methylumbelliferyl 4guanidinobenzoate; NPGB, 4'-nitrophenyl 4-guanidinobenzoate. 
To ensure that the cleavage of the ova was not affected by the inhibitors, untreated capacitated spermatozoa were mixed with the oocytes and after incubation for $4 \mathrm{~h}$, aminobenzamidine in culture medium was added at a final concentration of $100 \mu \mathrm{M}$. The $4 \mathrm{~h}$ time point was selected because Gwatkin, Andersen \& Williams (1974) have shown that a 90-95\% penetration of mouse ova occurs in vitro within $4 \mathrm{~h}$ of mixing the gametes. Incubation medium only was added to controls. The percentage of fertilization was essentially the same for the untreated (averaging 59.9\%) as for the treated gametes (averaging 62.5\%). The same results had been obtained previously with aminobenzamidine as well as with benzamidine and NPGB (Bhattacharyya et al., 1979). Additionally, throughout these experiments, the cleavage rate, i.e., the percentage of fertilized eggs that became two-celled embryos remained approximately the same (averaging $43.8 \%$ of the total fertilized ova) for both control and inhibitor treated groups, even though the fertilization rates for the latter were reduced. Thus, at the concentrations used, the inhibitors had no effect on the cleavage of the zygotes.

\section{Discussion}

Specific inhibitors of acrosin do not exist at the present time, although certain monosaccharides do inhibit human acrosin but not bovine or human pancreatic trypsin (Anderson, Oswald, Leto \& Zaneveld, 1980). Indirect evidence is necessary to establish that the proteinase inhibitors prevent fertilization through inhibition of acrosin. For this reason, dose-response curves of the inhibitors as antifertility agents were established to demonstrate that the inhibitory activity is specifically directed to the fertilization process. Although some general comparisons were reported previously (Bhattacharyya et al., 1979), the acrosin inhibitory activity of agents and their antifertility potency have not been compared before in detail in the same species.

The two different classes of proteinase inhibitors showed linear dose-response curves of antifertility effects with increasing concentrations of the inhibitors. The decrease in fertilization was not due to cytotoxicity because the compounds had no apparent effects on sperm motility or on ovum cleavage. These data show that the inhibitors specifically affect one or more components essential for sperm penetration into the egg. The dose response is probably the result of sperm populations which had their fertilizing component(s) sufficiently inhibited such that the number of fertile spermatozoa gradually decreased.

Because different test systems are necessary to determine the inhibitory activity of the agents towards mouse acrosin and towards fertilization, absolute comparisons of the relative activity of the inhibitors in both systems are difficult to make. However, the results obtained showed a remarkable similarity of activity of the agents in both systems. The difference in activity between aminobenzamidine and benzamidine as inhibitors of acrosin was almost the same as the difference in their antifertility activity. Their $K_{\mathrm{i}}$ values with acrosin $\left(5 \cdot 1 \times 10^{-4} \mathrm{M}\right.$ for benzamidine and $2.2 \times 10^{-5} \mathrm{M}$ for aminobenzamidine) were essentially identical to the $\mathrm{ED}_{30}$ values in the fertilization system $\left(2.3 \times 10^{-4} \mathrm{M}\right.$ for benzamidine and $2.7 \times 10^{-5} \mathrm{M}$ for aminobenzamidine). Furthermore, aminobenzamidine and benzamidine were 3-4 orders of magnitude less active in inhibiting fertilization than NPGB and MUGB, and were also orders of magnitude less potent in inhibiting acrosin. Exact activity comparisons between reversible and pseudo-irreversible inhibitors cannot be made because of the difference in their manner of interaction with the enzyme.

The determinations of $I_{50}$ were made for the interaction of the pseudo-irreversible inhibitors and acrosin at the $K_{\mathrm{m}}$ concentration of synthetic substrate which are not likely to reflect their potency in interacting with spermatozoa since the $I_{50}$ values express ideal circumstances. Additionally, NPBG and MUGB are unstable in solution, particularly at neutral or basic $\mathrm{pH}$. For these reasons, it is not surprising that more pseudo-irreversible inhibitor was necessary to prevent fertilization than to inhibit acrosin. However, the relative activity of the pseudo- 
irreversible inhibitors can be compared to each other. NPGB was approximately equally as potent as MUGB as an antifertility agent, and had similar activity as an inhibitor of mouse acrosin.

These results leave little doubt that acrosin is the major fertilizing component inhibited by the proteinase inhibitors. The exact physiological mechanism during fertilization that is prevented remains to be established. It has been proposed that acrosin is involved in (1) the acrosome reaction (Lui \& Meizel, 1979), (2) the penetration of the zona pellucida (Stambaugh, Brackett \& Mastroianni, 1969) and/or the vitelline membrane (Wolf, 1977), and (3) the binding of spermatozoa to the zona pellucida (Saling, 1982). Any one of these processes can be inhibited by the proteinase inhibitors.

Significant differences appear to exist among species with regard to the interaction of acrosin with substrates or inhibitors. It is essential that studies of the type reported here, are done in the same species. For example the Michaelis constant of BAEE hydrolysis by mouse acrosin $\mathbf{( 8 . 2}$ $\mu \mathrm{M})$ is lower than that by human $\alpha$-acrosin $(36 \mu \mathrm{M})$ (Anderson, Beyler, Mack \& Zaneveld, 1981). The inhibition constants $\left(K_{\mathrm{i}}\right.$ values) for benzamidine and aminobenzamidine are much higher for mouse acrosin $(510 \mu \mathrm{M}$ and $22 \mu \mathrm{M}$, respectively) than for human $\alpha$-acrosin $(30 \mu \mathrm{M}$ and $4 \mu \mathrm{M}$, respectively) (R. A. Anderson, S. A. Beyler \& L. J. D. Zaneveld, unpublished), and the $K_{\mathrm{i}}$ of benzamidine with boar acrosin is $4 \mu \mathrm{M}$ (Parrish et al., 1978). The $\mathrm{I}_{50}$ values for NPGB and MUGB are higher for human acrosin (7.0 $\mu \mathrm{M}$ and $5.5 \mu \mathrm{M}$, respectively) than mouse acrosin $(0.8$ $\mu \mathrm{M}$ and $0.98 \mu \mathrm{M}$, respectively) (R. A. Anderson, S. A. Beyler \& L. J. D. Zaneveld, unpublished).

The linearity of the dose-response curves for inhibitors in the mouse in-vitro fertilization system permits the $\mathrm{ED}_{50}$ of the inhibitors to be calculated and compared as is done for $\mathrm{LD}_{50}$ calculations in acute toxicity studies. Therefore, this test system can be used to determine the relative effectiveness of existing and newly developed proteinase (acrosin) inhibitors as antifertility agents. This system may become particularly useful in testing acrosin inhibitors as potential contraceptives. Inhibitors of acrosin are known to prevent conception when placed vaginally (Zaneveld, 1976; Joyce et al., 1979; Zaneveld et al., 1979). Screening these compounds as contraceptives through breeding experiments is relatively expensive and time consuming. The mouse in-vitro fertilization system allows for selection of the most potent inhibitors before initiating whole animal studies.

To date, the acrosin inhibitors used in antifertility studies have had certain drawbacks that have precluded their clinical applicability. Naturally occurring peptide inhibitors and a number of synthetic agents (including the benzamidine derivatives) bind acrosin reversibly and are probably removed from the spermatozoa during their migration through the female genital tract so that they have little practical use unless they are applied directly at the site of fertilization. Inhibitors which bind irreversibly to acrosin are contraceptive after vaginal administration, but have thus far been too toxic for clinical use. For example, $N$ - $\alpha$-tosyl-lysine chloromethyl ketone is an alkylating agent, and thus potentially carcinogenic, and NPGB releases 4-nitrophenol during reaction with a proteinase or upon non-specific hydrolysis. MUGB, however, possesses the high potency of NPGB but upon hydrolysis it releases 4-methylumbelliferone, a compound that is approved by the Food and Drug Administration (U.S.A.) as a therapeutic agent. The guanidinobenzoic acid portion of the molecule is also relatively non-toxic and similar compounds are used clinically. Thus, although acute and chronic toxicity tests with MUGB are necessary, and its antifertility activity in vivo needs to be assessed, the present results encourage further investigation of MUGB and related compounds as contraceptive agents.

This study was supported by NIH Grant No. HD 09868 and PARFR (AID) contract No. 204. We thank Dr J. M. Reddy and Dr R. Stark for their guidance with the in-vitro fertilization technique and to Ms Mary Y. Jarosz for her secretarial assistance. 


\section{References}

Anderson, R.A., Oswald, C., Leto, S. \& Zaneveld, L.J.D. (1980) Inhibition of acrosin by fructose and other related monosaccharides. Biol. Reprod. 22, 10791082.

Anderson, R.A., Beyler, S.A., Mack, S.R. \& Zaneveld, L.J.D. (1981) Characterization of a high molecular weight form of acrosin: comparison with human trypsin. Biochem. J. 199, 307-316.

Bedford, J.M. \& Cross, N.L. (1978) Normal penetration of rabbit spermatozoa through a trypsin- and acrosin-resistant zona pellucida. $J$. Reprod. Fert. 54, 385-392.

Bhattacharyya, A.K., Goodpasture, J.D. \& Zaneveld, L.J.D. (1979) Acrosin of mouse spermatozoa. Am.J. Physiol. 237, E40-E44.

Dixon, M. (1953) The determination of enzyme inhibitor constants. Biochem. J. 55, 170-171.

Greenslade, F.C., Hahn, D.M. \& Homm, R.E. (1977) The rabbit as an in-vivo animal model for the study of vaginal contraceptive potency. In Risks, Benefits, and Controversies in Fertility Control, pp. 534-546. Eds J. J. Sciarra, G. I. Zatuchni \& J. Speidel. Harper and Row, Hagerstown, Maryland.

Gwatkin, R.B.L., Andersen, O.F. \& Williams, D.T. (1974) Capacitation of mouse spermatozoa in vitro: involvement of epididymal secretions and cumulus oophorus. J. Reprod. Fert. 41, 253-256.

Joyce, C., Freund, M. \& Peterson, R.N. (1979) Contraceptive effects of intravaginal application of acrosin and hyaluronidase inhibitors in rabbits. Contraception 19, 95-100.

Lowry, O.H., Rosebrough, M.J., Farr, A.L. \& Randall, R.J. (1951) Protein measurement with the folin phenol reagent. J. Biol. Chem. 193, 265-275.

Lui, C.W. \& Meizel, S. (1979) Further evidence in support of a role for hamster sperm hydrolytic enzymes in the acrosomal reaction. J. Exp. Zool. 297, 173-186.

Morton, D.B. (1976) Lysosomal enzymes in mammalian spermatozoa. In Lysosomes in Biology and
Pathology, Vol. 5, pp. 203-255. Eds J. T. Dingle \& R. T. Dean. North Holland Publishing Co., Amsterdam.

Morton, D.B. (1977) The occurrence and function of proteolytic enzymes in the reproductive tract of mammals. In Proteinases in Mammalian Cell and Tissues, pp. 445-500. Ed. A. J. Barrett. North Holland Publ. Co., New York.

Parrish, R.F., Straus, J.W., Paulson, J.D., Polakoski, K.L., Tidwell, R.R., Geratz, J.D. \& Stevens, J.M. (1978) Structure-activity relationships for the inhibition of acrosin by benzamidine derivatives. $J$. med. Chem. 21, 1132-1136.

Saling, P.M. (1982) Involvement of trypsin-like activity in binding of mouse spermatozoa to zonae pellucidae. Proc. natn, Acad. Sci., U.S.A. 78, 6231-6235.

Schwert, G.W. \& Takenaka, Y. (1955) A spectrophotometric determination of trypsin and chymotrypsin. Biochem. Biophys. Acta 16, 570-575.

Stambaugh, R., Brackett, B.G. \& Mastroianni, L. (1969) Inhibition of in-vitro fertilization of rabbit ova by trypsin inhibitors. Biol. Reprod. 1, 223-227.

Toyoda, Y. \& Chang, M.C. (1974) Fertilization of rat eggs in vitro by epididymal spermatozoa and the development of eggs following transfer. J. Reprod. Fert. 36, 9-22.

Wolf, D.P. (1977) Involvement of a trypsin-like activity in sperm penetration of zona-free mouse ova. J. exp. Zool. 199, 149-156.

Zaneveld, L.J.D. (1976) Sperm enzyme inhibitors as antifertility agents. In Human Semen and Fertility Regulation in Men, pp. 570-580. Ed. E. S. E. Hafez. C. V. Mosby Co., St Louis.

Zaneveld, L.J.D., Beyler, S.A., Kim, D.S. \& Bhattacharyya, A.K. (1979) Acrosin inhibitors as vaginal contraceptives in the primate and their acute toxicity. Biol. Reprod. 20, 1045-1054.

Received 1 December 1981 